\title{
Cost of stroke: a controlled national study evaluating societal effects on patients and their partners
}

Poul Jennum ${ }^{1,4^{*}+}$, Helle K. Iversen ${ }^{2,4 \dagger}$, Rikke Ibsen ${ }^{3,4 \dagger}$ and Jakob Kjellberg ${ }^{2,4 \dagger}$

\begin{abstract}
Background: To estimate the direct and indirect costs of stroke in patients and their partners.

Description: Direct and indirect costs were calculated using records from the Danish National Patient Registry from 93,047 ischemic, 26,012 hemorrhagic and 128,824 unspecified stroke patients and compared with 364,433, 103,741 and 500,490 matched controls, respectively.

Results: Independent of age and gender, stroke patients had significantly higher rates of mortality, health-related contacts, medication use and lower employment, lower income and higher social-transfer payments than controls. The attributable cost of direct net health care costs after the stroke (general practitioner services, hospital services, and medication) and indirect costs (loss of labor market income) were $€ 10,720, € 8,205$ and $€ 7,377$ for patients, and $€ 989, € 1,544$ and $€ 1.645$ for their partners, over and above that of controls for hemorrhagic, ischemic and unspecified stroke, respectively. The negative social- and health-related status could be identified up to eleven years before the first diagnosis.
\end{abstract}

Conclusion: Stroke has significant mortality, morbidity and socioeconomic consequences for patients, their partners and society.

Keywords: Stroke, Illness and health care costs, Economic burden, Employment, Partner, Social

\section{Background}

A significant proportion of the population will experience stroke in their lifetime. The outcomes of stroke range from full remission to severe disability and death, and the event causes significant personal, familiar and societal burdens.

In the past 20 years significant progress has been made towards identifying risk factors and the early stages of stroke, managing the condition, and developing early primary and secondary interventions. Stroke is associated with high cardiovascular risk factors, including hypertension, smoking, sedentary lifestyle, obesity, reduced quality of life, depression or anxious mood, low income, social interaction, and social status [1]. Previous studies examining the burden of stroke have focused on the direct costs,

\footnotetext{
* Correspondence: poul.joergen.jennum@regionh.dk

${ }^{\dagger}$ Equal contributors

'Danish Center for Sleep Medicine, Department of Clinical Neurophysiology, Faculty of Health Sciences, University of Copenhagen, Glostrup Hospital, DK 2600, Copenhagen, Glostrup, Denmark

${ }^{4}$ Danish Institute for Health Services Research, Copenhagen, Denmark

Full list of author information is available at the end of the article
}

e.g., hospital services and the use of treatment procedures, such as medication, thrombolysis, physiotherapy, etc., as well as the reduction in quality of life, and indirect costs [2-7]. Most studies have evaluated case series, models, or quality of life. A number of studies have sought to evaluate the impact of stroke at a national level [8-13], and upon caregivers after the stroke [14-17]. However, no studies have evaluated the health and social burden before the stroke on patients and their partners in terms of the total socioeconomic costs before and after the stroke incident.

The objective of the current study was to use a national patient database to evaluate the cost of stroke to patients, their partners and society, and, using a case-control design, to examine the associations of pre-existing morbidity, social factors, and economic status with stroke and its consequences.

\section{Construction and content}

The NPR contains information about diagnosis, procedures (diagnostic, treatment). The National Health Security contains all information regarding healt contacts 
in primary sector and the Danish Medicine Agency includes all information regarding prescripting medication.

\section{Utility and Discussion}

All data are recorded in the dataset by each health contact in the healthcare sector for all national patients. The user interface is recorded via a dedicated software systems.

\section{Methods}

In Denmark, it is possible to calculate health sector costs and productivity losses related to diseases because information from public and private hospitals, general practice, and privately practicing specialists, and data about medication, social transfers, labor market income and employment for all Danes are registered in central databases. Health care in Denmark is predominantly publicly funded, and all patient contacts with the hospital system are recorded in the Danish National Patient Registry (NPR) at the time of contact; this information includes the primary diagnosis [18]. The NPR is a time-based national database that includes data from all inpatient and outpatient contacts, which means that the data we can extract are representative of all patients in Denmark who have received a diagnosis of stroke in the primary or secondary sector in a public or private hospital. Since data are available for the entire observation period, we can trace patients retrospectively and prospectively, relative to the time of the diagnosis. Furthermore, all contacts in the primary sector (general practice and specialist practices) and the use of medications are recorded in the databases of the National Health Security and the Danish Medicine Agency, respectively. All national patients with a diagnosis of stroke are included.

The economic consequences of stroke for patients and their partners were estimated by determining the yearly cost of illness per patient diagnosed with the ICD-10 code for stroke (I61: cerebral hemorrhage; I63: brain infarction; I64: stroke not otherwise defined whether due to infarction or hemorrhage); these codes are assigned after patient evaluation in each hospital (based on a standardized evaluation of stroke), and comparing the figure with that of a matched control group. The model for deriving these estimates has been described elsewhere [19-22].

By reviewing the NPR, we identified all patients who received a first diagnosis of stroke between 1997 and 2009. Then, using data from the Civil Registration System Statistics Denmark database (which includes information about social factors, marital and cohabiting status, incomes, pensions, etc.) [23], we randomly selected citizens of the same age and sex as the patients. Social compensation was taken into account by selecting control subjects who resided in the same area of the country in which the patients lived, and who had the same civil status. The ratio of control subjects to patients was 4:1. Data from patients and matched control subjects who could not be identified in Statistics Denmark using the Civil Personal Registration (CPR) System database were excluded from the sample. More than $99 \%$ of the observations in the two groups were successfully matched. Patients and matched control subjects were followed from the year of diagnosis until 2009. Thus, patients with a stroke at the beginning of the period contributed follow-up data over 11 years; those experiencing a stroke at the end of the period provided pre-data, and all those in between provided varying amounts of both pre- and post-data. If a patient or control was not present in the CPR register on January $1^{\text {st }}$ each year, then the corresponding control or patient control was not included in the dataset for that year. Patients absent from the CPR register are typically deceased, in prison, or have emigrated to another country. All patients' partners (married or unmarried, and irrespective of gender) were also identified. A similar control group of partners was identified on the basis of age, gender and socio-demographic status.

The health care costs were then divided into annual direct and indirect health care costs. Direct costs, including hospitalization and outpatient costs, were calculated using diagnosis-related group (DRG) weights, and specific

Table 1 Age distribution of stroke patients included in the study

\begin{tabular}{|c|c|c|c|c|c|c|c|c|c|}
\hline \multirow[b]{2}{*}{ Age } & \multicolumn{3}{|c|}{ Hemorrhagic stroke } & \multicolumn{3}{|c|}{ Ischemic stroke } & \multicolumn{3}{|c|}{ Stroke (NOS) } \\
\hline & Patients & Controls & $\%$ & Patients & Controls & $\%$ & Patients & Controls & $\%$ \\
\hline$<20$ & 296 & 1,184 & 1.1 & 285 & 1,139 & 0.3 & 102 & 408 & 0.1 \\
\hline $20-29$ & 344 & 1,375 & 1.3 & 376 & 1,504 & 0.4 & 571 & 2,282 & 0.5 \\
\hline $30-39$ & 662 & 2,647 & 2.6 & 1,300 & 5,194 & 1.4 & 1,877 & 7,503 & 1.5 \\
\hline $40-49$ & 1,766 & 7,063 & 6.8 & 4,621 & 18,450 & 5.1 & 5,775 & 23,041 & 4.6 \\
\hline $50-59$ & 3,587 & 14,328 & 13.8 & 11,847 & 47,140 & 12.9 & 14,494 & 57,578 & 11.5 \\
\hline $60-69$ & 5,188 & 20,715 & 20.0 & 20,028 & 78,998 & 21,7 & 24,817 & 97,675 & 19.5 \\
\hline $70-79$ & 6,940 & 27,670 & 26.7 & 26,674 & 104,277 & 28.6 & 37,310 & 144,910 & 29.0 \\
\hline$\geq 80$ & 7,229 & 28,759 & 27.7 & 27,916 & 107,731 & 29.6 & 43,878 & 167,093 & 33.4 \\
\hline All & 26012 & 103,741 & 100 & 93,047 & 364,433 & 100 & 128,824 & 500,490 & 100 \\
\hline
\end{tabular}

NOS not otherwise specified 


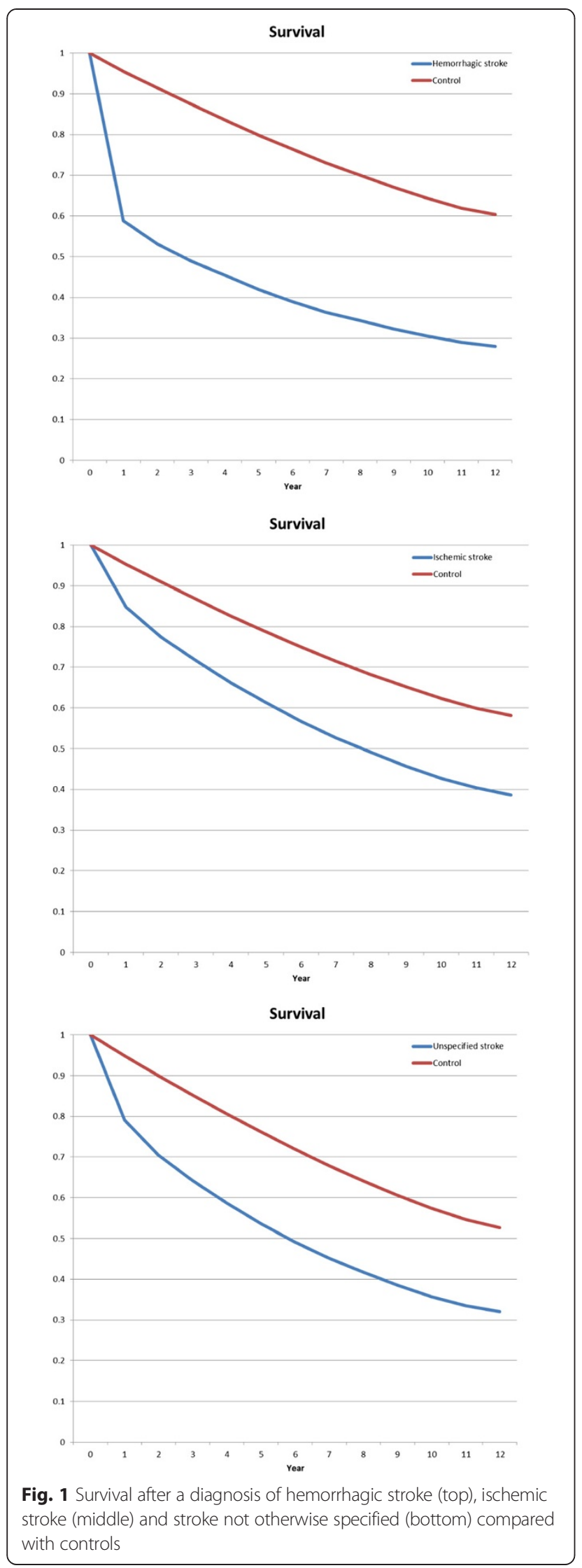

outpatient tariffs. These cost estimates were all based on data from the Danish Ministry of Health. The use and costs of drugs were derived from data from the Danish Medicines Agency. The retail price of each drug (including dispensing costs) was multiplied by the number of transactions. The frequencies and costs of consultations with general practitioners and other specialists were based on data from the National Health Security.

The indirect costs, which are those related to reduced labor supply, are based on figures from Danish Income Statistics. Social-transfer payments, which in Denmark are primarily publicly funded, were also included; they include subsistence allowances, pensions, social security, social assistance, publicly funded personal support for education, and others. Cost-of-illness studies measure the economic burden resulting from disease and illness across a defined population and include direct and indirect costs. Direct costs are the value of resources used for the treatment, care and rehabilitation of people with the condition under study. Indirect costs are the value of economic resources lost through disease-related work disability or premature mortality. As patients leave the national data registers at the time of death, the indirect cost estimate comprises only the production loss related to disease-related work disability. The human capital approach is used to measure the productivity costs based on the difference in labor market income between the cases and the matched controls. It is important to distinguish costs from monetary transfer payments such as disability and welfare payments. These payments represent a transfer of purchasing power to the recipients from general taxpayers but do not constitute net increases in the use of resources and are, therefore, not included in the total cost estimate.

In the Danish Stroke Register (formerly the National Indicator Project, NIP), it was possible to choose the diagnoses of ischemic stroke, hemorrhagic stroke or unspecified stroke. Although all patients with stroke underwent a CT or MRI scan, some stroke units customarily classified ischemic strokes as unspecified strokes, and these were the diagnoses reported to the Danish National Patient Registry. In the present study, a total of 247,883 strokes were considered. The expected distribution of stroke types would be $15 \%$ hemorrhagic strokes, corresponding to 37,183 patients. In fact, only 26,012 patients ( $10.5 \%$ of the total) were registered as hemorrhagic strokes, so 11,171 patients with hemorrhagic stroke were assigned to the unspecified group, equivalent to $9 \%$ of the unspecified group, although $91 \%$ were ischemic strokes. The register no longer permits a diagnosis of unspecified stroke, and in 2014 the distribution was $87 \%$ ischemic and $13 \%$ hemorrhagic strokes. The diagnoses have been validated previously [24].

Costs were measured on a yearly basis and adjusted to 2009 prices using the general price index. All costs were measured in DKK and converted to Euros $(€ 1=$ DKK 7.45). 
Table 2 Distribution of health care consumed and income in stroke patients after diagnosis and in corresponding controls (percentage)

\begin{tabular}{|c|c|c|c|c|c|c|c|c|c|}
\hline & Hemo & gic stroke & & Ischer & roke & & Stroke & & \\
\hline & Case & Control & $P$ & Case & Control & $P$ & Case & Control & $P$ \\
\hline Outpatient treatment & 59.2 & 36.6 & $<0.001$ & 59.4 & 37.5 & $<0.001$ & 59.3 & 38.1 & $<0.001$ \\
\hline Inpatient treatment & 57.9 & 20.5 & $<0.001$ & 54.8 & 21.6 & $<0.001$ & 54.2 & 22.5 & $<0.001$ \\
\hline Medication & 93.3 & 85.1 & $<0.001$ & 97.8 & 86.3 & $<0.001$ & 97.3 & 87.4 & $<0.001$ \\
\hline Public health insurance & 97.4 & 95.7 & $<0.001$ & 99.0 & 96.0 & $<0.001$ & 98.8 & 96.0 & $<0.001$ \\
\hline Income from employment & 21.0 & 28.6 & $<0.001$ & 18.2 & 24.5 & $<0.001$ & 16.2 & 21.4 & $<0.001$ \\
\hline Public transfer income total & 86.6 & 77.9 & $<0.001$ & 89.8 & 81.7 & $<0.001$ & 90.3 & 84.0 & $<0.001$ \\
\hline Pension & 55.9 & 60.0 & $<0.001$ & 64.4 & 65.8 & $<0.001$ & 67.7 & 70.3 & $<0.001$ \\
\hline Other public transfers & 25.3 & 15.3 & $<0.001$ & 21.2 & 14.2 & $<0.001$ & 19.3 & 12.2 & $<0.001$ \\
\hline Sickpay (public-funded) & 9.8 & 4.2 & $<0.001$ & 7.8 & 3.3 & $<0.001$ & 6.1 & 2.8 & $<0.001$ \\
\hline
\end{tabular}

NOS not otherwise specified

Survival was analyzed by the Kaplan-Meier method. The resulting survival curves take into account the censoring of data that arises since not all patients died before the end of the analysis period. The survival curves are stratified into case and control groups, and show the estimates of the survival distribution function.

The study was approved by the Danish Data Protection Agency. Data were handled in a manner that did not reveal the identity of any patients or control subjects, so neither individual nor ethical approval was required. Statistical analysis was done with SAS 9.1.3 (SAS, Inc., Cary, NC). Statistical significance of the cost estimates was assessed by nonparametric bootstrap analysis (33).

\section{Results}

93,047 ischemic, 26,012 hemorrhagic and 128,824 stroke NOS patients were registered. They were compared with 364,433, 103,741 and 500,490 matched controls, respectively, identified from the National Danish Patient Registry. In addition, partners of patients in the case group were matched with partners in the matched control group. Almost half of the patients in the patient group had a partner. Mean (95 \% CI) ages were 68.5 (68.3-68.7), 79.9 (79.871.0), and 72.2 (72.1-7.3) years for ischemic, hemorrhagic, and NOS stroke, respectively (Table 1).

\section{Survival in stroke}

Ten-year survival was significantly lower in stroke patients than in their respective controls $(p<0.001): 0.305$ (95\% CI, 0.298-0.312) vs. $0.643(0.539-0.647)$ for hemorrhagic, $0.428(0.423-0.432)$ vs. 0.624 (0.621-9.626) for ischemic, and $0.357(0.354-0.360)$ vs. $0.574(0.572-0.576)$ for unspecified stroke patients (all comparisons, $p<0.0001$ ). Twelve-year survival for hemorrhagic, ischemic stroke and stroke NOS is shown in Fig. 1. Lower survival tended to reduce the total health care costs. We did not adjust for the potential costs of those people who died since there is no accepted model for evaluating diseases with high mortality.

\section{Direct costs from outpatient, inpatient and primary care, and drug consumption}

More patients and their partners than respective control subjects were treated in outpatient clinics, were hospitalized, used medication and had contact with the primary care system (Tables 2 and 3 ).

Indirect costs, social costs, employment rate and income Greater proportions of patients and their partners received help from social services compared with control subjects and their partners. The statistically significant differences in employment rates (Tables 4 and Fig. 2) and income from employment were smaller before the injury, whereas the highest social-transfer rates were seen before the diagnosis and increased thereafter (not shown). Income increased in partners after the patients' injury relative to controls (Fig. 2).

\section{Total health care costs per year}

The sources of information and the average annual health care cost per person-year by cost category for patients with stroke in Denmark compared with age- and sex-matched control subjects before and after diagnosis are presented in Table 4; the corresponding numbers for their partners are shown in Table 5 (supplementary file). The attributable cost of direct net health care costs after the stroke (general practitioner services, hospital services, and medication) and indirect costs (loss of labor market income) were $€ 10,720$, $€ 8,205$, and $€ 7,377$ for patients, and $€ 989, € 1,544$, and $€ 1.645$ for their partners (Table 5) over and above that of controls for hemorrhagic, ischemic, and unspecified stroke, respectively. The majority of the difference in health care costs for the patients were incurred in the first year of the disease, when the differences in health care costs were $€ 17.220$, €13.913, and $€ 13.259$. The average incremental 
Table 3 Health care costs of stroke in patients before and after diagnosis

\begin{tabular}{|c|c|c|c|c|c|c|c|c|c|}
\hline & Hemorrhagic & Control & $P$ & Ischemic & Control & $P$ & Stroke NOS & Control & $P$ \\
\hline \multicolumn{10}{|l|}{ Before diagnosis } \\
\hline$N$ & 141,389 & 562,781 & & 547,465 & $2,129,024$ & & 628,432 & $2,416,189$ & \\
\hline Outpatient treatment & 341 & 233 & $<0.001$ & 315 & 240 & $<0.001$ & 335 & 234 & $<0.001$ \\
\hline Inpatient treatment & 1,758 & 1,030 & $<0.001$ & 1,539 & 1,019 & $<0.001$ & 1,715 & 1,033 & $<0.001$ \\
\hline Medication & 592 & 466 & $<0.001$ & 600 & 475 & $<0.001$ & 649 & 478 & $<0.001$ \\
\hline Public health insurance & 335 & 283 & $<0.001$ & 325 & 284 & $<0.001$ & 353 & 288 & $<0.001$ \\
\hline Income from employment & 9.654 & 12.469 & $<0.001$ & 9,438 & 11,908 & $<0.001$ & 8,413 & 11,213 & $<0.001$ \\
\hline Public transfer income total & 11,991 & 10,877 & & 12,333 & 11,365 & & 12,804 & 11,645 & \\
\hline Pension & 7,936 & 7,814 & $<0.001$ & 8,360 & 8,187 & $<0.001$ & 8,979 & 8,722 & $<0.001$ \\
\hline Other public transfers & 3,728 & 2,850 & $<0.001$ & 3,678 & 2,979 & $<0.001$ & 3,533 & 2,736 & $<0.001$ \\
\hline Sickpay (public-funded) & 328 & 213 & $<0.001$ & 295 & 199 & $<0.001$ & 292 & 187 & $<0.001$ \\
\hline Direct health care costs & 3,026 & 2,013 & & 2,778 & 2,018 & & 3,051 & 2,032 & \\
\hline Indirect costs, foregone earnings & 2,815 & & & 2,470 & & & 2,800 & & \\
\hline Sum of direct and indirect costs & 5,840 & 2,013 & & 5,248 & 2,018 & & 5,851 & 2,032 & \\
\hline Net costs & 3,827 & & & 3,231 & & & 3,819 & & \\
\hline Social transfer payments & 11,991 & 10,877 & & 12,333 & 11,365 & & 12,804 & 11,645 & \\
\hline \multicolumn{10}{|l|}{ After diagnosis } \\
\hline$N$ & 89,043 & 569,616 & & 398,140 & $1,869,080$ & & 566,620 & $2,862,856$ & \\
\hline Outpatient treatment & 664 & 396 & $<0.001$ & 679 & 424 & $<0.001$ & 665 & 409 & $<0.001$ \\
\hline Inpatient treatment & 7,840 & 1,814 & $<0,001$ & 5,986 & 1,906 & $<0.001$ & 5,904 & 1,981 & $<0.001$ \\
\hline Medication & 924 & 605 & $<0.001$ & 1,134 & 632 & $<0.001$ & 1,119 & 642 & $<0.001$ \\
\hline Public health insurance & 659 & 354 & $<0.001$ & 632 & 363 & $<0.001$ & 609 & 363 & $<0.001$ \\
\hline Income from employment & 6,165 & 9,965 & $<0.001$ & 5,196 & 8,294 & $<0.001$ & 4,875 & 7,350 & $<0.001$ \\
\hline Public transfer income total & 13,395 & 12,051 & & 14,149 & 12,832 & & 14,070 & 13,185 & \\
\hline Pension & 8,328 & 9,693 & $<0.001$ & 10,091 & 10,650 & $<0.001$ & 10,306 & 11,225 & $<0.001$ \\
\hline Other public transfers & 4,222 & 2,149 & $<0.001$ & 3,462 & 2,015 & $<0.001$ & 3,289 & 1,816 & $<0.001$ \\
\hline Sickpay (public-funded) & 846 & 209 & $<0.001$ & 596 & 167 & $<0.001$ & 474 & 145 & $<0.001$ \\
\hline Direct health care costs & 10,088 & 3,168 & & 8,431 & 3,324 & & 8,297 & 3,395 & \\
\hline Indirect costs, foregone earnings & 3,800 & & & 3,098 & & & 2,475 & & \\
\hline Sum of direct and indirect costs & 13,888 & 3,168 & & 11,529 & 3,324 & & 10,772 & 3,395 & \\
\hline Attributable costs & 10,720 & & & 8,205 & & & 7,377 & & \\
\hline Social transfer payments & 13,395 & 12,051 & & 14,149 & 12,832 & & 14,070 & 13,185 & \\
\hline
\end{tabular}

NOS not otherwise specified

health care costs during the first 5 years after the stroke were $€ 2.771, € 2.515$, and $€ 2.432$.

Social-transfer payments were all significantly greater in stroke patients than in control subjects.

\section{Influence of age and sex on employment and direct and indirect costs}

The relationships between age and sex on one hand, and direct and indirect costs on the other were stronger after the diagnosis in patients than in controls, for all age groups. On average, male patients and controls had higher incomes than their female counterparts. Age and sex had pronounced effects on direct costs; in particular, there were greater expenses due to hospitalization and medication among younger patients, whereas direct and indirect costs were higher among younger adults, due to increased indirect costs (data for ischemic stroke are shown in Fig. 2 for patients and their controls; the patterns for the other stroke diagnoses were similar).

\section{Discussion}

The study has several important findings. Stroke patients already present a significant burden before their stroke. Stroke has significant economic consequences: patients and 
Table 4 Distribution of health care received and income in partners after diagnosis and in corresponding controls (percentage)

\begin{tabular}{|c|c|c|c|c|c|c|c|c|c|}
\hline & \multicolumn{3}{|c|}{ Hemorrhagic stroke } & \multicolumn{3}{|c|}{ Ischemic stroke } & \multicolumn{3}{|c|}{ Stroke NOS } \\
\hline & Partner & Control & $P$ & Partner & Control & $P$ & Partner & Control & $P$ \\
\hline Outpatient treatment & 34.3 & 35.2 & $<0.001$ & 36.4 & 35.6 & 0.067 & 59.3 & 38.1 & $<0.001$ \\
\hline Inpatient treatment & 16.2 & 16.4 & 0.169 & 17.3 & 16.7 & $<0.001$ & 54.2 & 22.5 & $<0.001$ \\
\hline Medication & 83.8 & 84.3 & 0.001 & 86.7 & 85.6 & $<0.001$ & 97.3 & 87.4 & $<0.001$ \\
\hline Public health insurance & 96.8 & 96.8 & 0.100 & 97.1 & 97.0 & 0.656 & 98.8 & 96.0 & $<0.001$ \\
\hline Income from employment & 40.5 & 37.8 & $<0.001$ & 33.1 & 34.3 & $<0.001$ & 16.2 & 21.4 & $<0.001$ \\
\hline Public transfer income total & 70.9 & 71.0 & 0.012 & 76.9 & 74.0 & $<0.001$ & 90.3 & 84.0 & $<0.001$ \\
\hline Pension & 43.5 & 47.6 & $<0.001$ & 50.4 & 51.1 & $<0.001$ & 67.7 & 70.3 & $<0.001$ \\
\hline Other public transfers & 22.7 & 20.0 & $<0.001$ & 23.3 & 20.3 & $<0.001$ & 19.3 & 12.2 & $<0.001$ \\
\hline Sickpay (public-funded) & 7.9 & 6.1 & $<0.001$ & 6.0 & 5.1 & $<0.001$ & 6.1 & 2.8 & $<0.001$ \\
\hline
\end{tabular}

NOS not otherwise specified

their partners had significantly higher rates of contact with all sectors of the health care system than did age- and sexmatched control subjects. This covers contact with general practice, outpatient clinics, and in-hospital services, as well as medication use, and publicly supported payment for medication. Total expenses for stroke patients were more than four times those for the controls. Patients had lower employment rates but received welfare payments significantly more often than controls. Employed patients had lower incomes than employed control subjects. However, the cost estimates are lower, as some previous studies have found. This is probably because 1) we compared patients with a control group who may have diseases other than stroke, 2) the study did not include the cost of home nursing and nursing homes, and 3) in the aging population under consideration, a higher proportion of patients than controls are on a pension, which reduces the indirect costs.

Stroke has a significant influence on patients' partners: health care contacts were more frequent in the secondary health care system, in which partners made greater demands on the social care system, and consequently incurred greater direct and indirect costs. Stroke causes significant mortality and morbidities; the mortality rates in the data are presented, but we were not able to include loss of life in the cost estimates as there are no valid methods for estimating these consequences.

It is of particular note that stroke patients and their partners tended to experience pre-existing social, economic and morbidity effects several years before the incident. These effects are considerable and present more than 10 years before the stroke incident. This is to be expected since strokes are often the consequence of major cardiovascular and other risk factors (e.g., lifestyle factors), so that stroke cases often suffer from other comorbidities.

The differences between patients with stroke and control subjects were as considerable as those for patients with chronic neurological diseases [19-22, 25]. Given the large numbers of people involved and the differential effects by age and gender, the personal, familiar and societal costs are considerable.

Previous studies have documented the effect of stroke on partners with respect to quality of life, perceived health, and social effects $[7,15,17,26-30]$. We found that stroke had a significant impact on health consumption and social effects on caregivers, leading to higher direct and indirect costs. They arose from increased health care usage and lower income levels. Partners' incomes did not increase to compensate for the drop in the income of patients with chronic disease, and, in fact, actually tended to decrease. Such effects have been observed for people with serious fatal neurological diseases like amyotrophic lateral sclerosis, whose partners compensate for the loss of social welfare by increasing their own income level. [31] This is probably due to several factors: the disease also affects younger individuals, causes loss of social competences, and there may be more focus on families than on stroke patients. However, stroke sequelae affect the partner in several ways, resulting in increased morbidity and use of medication, and work capability and income.

At the time of the diagnosis, patients already presented significant role limitations. Such limitations have been described in other chronic and progressive disorders, such as multiple sclerosis [32], Parkinsonism, narcolepsy [33], and sleep-disordered breathing, although these are associated with long-lasting and pre-diagnostic courses. This cannot be explained solely by the stroke. Stroke patients, reported to the NPR, showed significant worsening of social and health care costs variables a long time before their diagnosis. This difference cannot be explained by the choice of the control group since we selected the group from similar social areas. The pre-existing socioeconomic load may instead be associated with the occurrence of other comorbidities, social factors, and fatigue [34, 35], amongst other factors. Further evaluation of pre- 


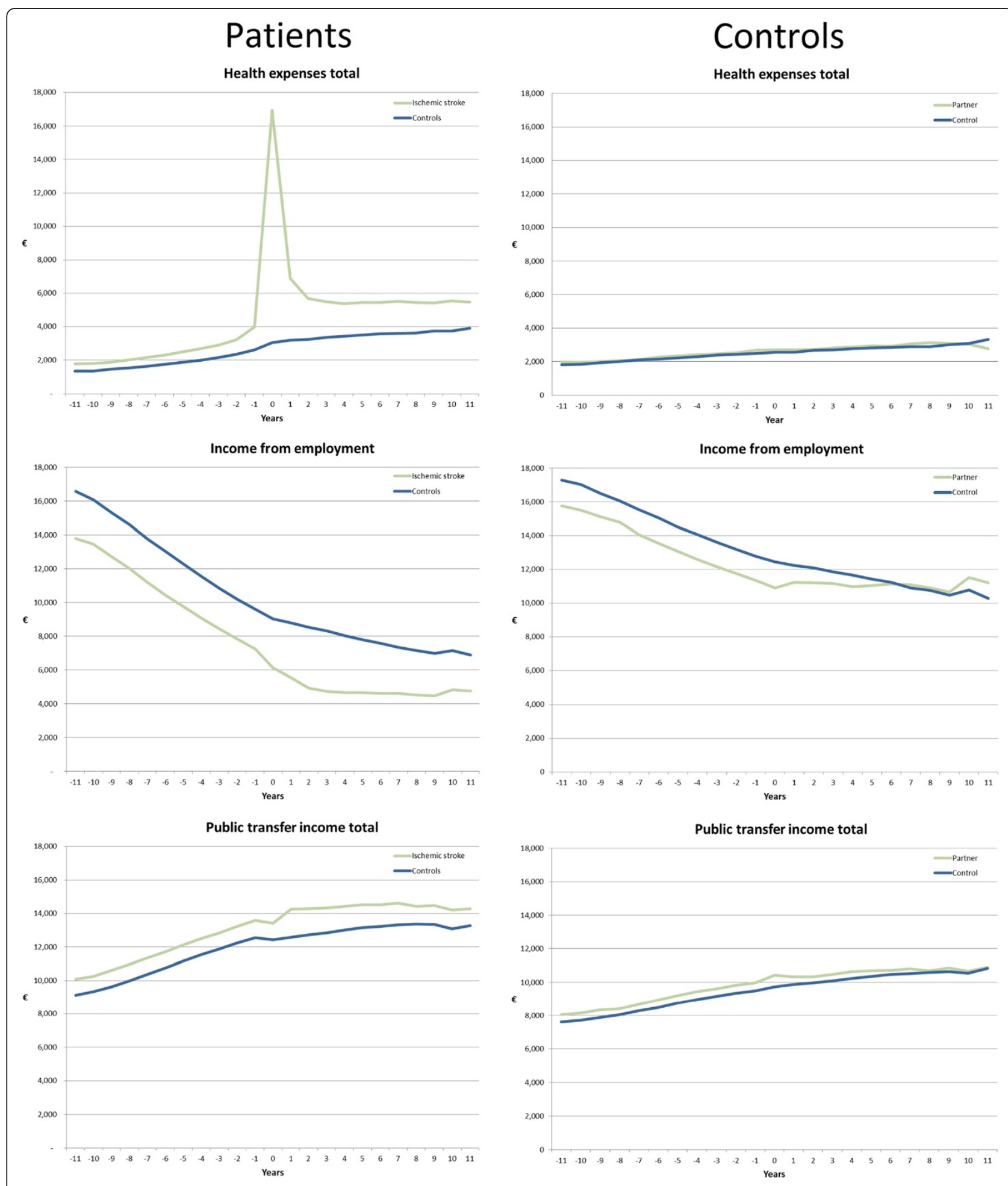

Fig. 2 Total health expenses, income from employment, and social transfer of income in patients with ischemic stroke and their partners compared with respective controls before and after diagnosis (patients with hemorrhagic and stroke NOS show similar patterns)

existing comorbidities should enable these issues to be addressed.

The occurrence and management of stroke tend to follow a social gradient [36, 37], which we have further investigated in this study. In order to control potential negative social effects of stroke we used selection of controls using geographic but not full social compensation (e.g., by income or education). 
Table 5 Health care costs and income of partners of patients before and after diagnosis (Euros)

\begin{tabular}{|c|c|c|c|c|c|c|c|c|c|}
\hline & Hemorrhagic & Control & $P$ & Ischemic & Control & $P$ & Stroke NOS & Control & $P$ \\
\hline \multicolumn{10}{|l|}{ Before diagnosis } \\
\hline$N$ & 80,184 & 327,758 & & 315,730 & $1,256,233$ & & 345,920 & $1,366,131$ & \\
\hline Outpatient treatment & 272 & 265 & 0.163 & 276 & 271 & 0.087 & 284 & 272 & $<0.001$ \\
\hline Inpatient treatment & 1,267 & 1,218 & 0.100 & 1,317 & 1,237 & $<0.001$ & 1,370 & 1,283 & $<0.001$ \\
\hline Medication & 459 & 449 & 0.002 & 479 & 459 & $<0.001$ & 487 & 465 & $<0.001$ \\
\hline Public health insurance & 294 & 287 & $<0.001$ & 292 & 289 & $<0.001$ & 301 & 295 & $<0.001$ \\
\hline Income from employment & 14,029 & 14,946 & $<0.001$ & 12,938 & 14,374 & $<0.001$ & 12,471 & 14,000 & $<0.001$ \\
\hline Public transfer income total & 8,955 & 8,686 & & 9,257 & 8,808 & & 9,409 & 8,956 & \\
\hline Pension & 5,336 & 5,131 & $<0.001$ & 5,271 & 5,172 & $<0.001$ & 5,666 & 5,492 & $<0.001$ \\
\hline Other public transfers & 3,301 & 3,250 & 0.054 & 3,674 & 3,353 & $<0.001$ & 3,458 & 3,197 & $<0.001$ \\
\hline Sickpay (public-funded) & 318 & 304 & 0.410 & 312 & 282 & $<0.001$ & 285 & 267 & $<0.001$ \\
\hline Direct health care costs & 2,291 & 2,219 & & 2,364 & 2,256 & & 2,441 & 2,315 & \\
\hline Indirect costs, foregone earnings & 917 & & & 1,436 & & & 1,529 & & \\
\hline Sum of direct and indirect costs & 3,208 & 2,219 & & 3,800 & 2,256 & & 3,970 & 2,315 & \\
\hline Attributable costs & 989 & & & 1,544 & & & 1,654 & & \\
\hline Social transfer payments & 8,955 & 8,686 & & 9,257 & 8,808 & & 9,409 & 8,956 & \\
\hline \multicolumn{10}{|l|}{ After diagnosis } \\
\hline$N$ & 43,817 & 300,413 & & 203,082 & 978,759 & & 274,066 & $1,403,525$ & \\
\hline Outpatient treatment & 366 & 394 & 0.010 & 410 & 409 & 1,000 & 399 & 399 & 1,000 \\
\hline Inpatient treatment & 1,373 & 1,380 & 1,000 & 1,471 & 1,408 & $<0.001$ & 1,548 & 1,472 & $<0.001$ \\
\hline Medication & 488 & 509 & $<0.001$ & 555 & 531 & $<0.001$ & 565 & 548 & $<0.001$ \\
\hline Public health insurance & 345 & 344 & 1,000 & 360 & 356 & $<0.001$ & 362 & 360 & 0.010 \\
\hline Income from employment & 14,429 & 13,522 & $<0.001$ & 11,082 & 11,841 & $<0.001$ & 10.908 & 11,146 & $<0.001$ \\
\hline Public transfer income total & 9,643 & 9,575 & & 10.492 & 10.082 & & 10.480 & 10.217 & \\
\hline Pension & 6,169 & 6,623 & $<0.001$ & 6,961 & 7,118 & $<0.001$ & 7,086 & 7,406 & $<0.001$ \\
\hline Other public transfers & 3,067 & 2,644 & $<0.001$ & 3,227 & 2,713 & $<0.001$ & 3,108 & 2,584 & $<0.001$ \\
\hline Sickpay (public-funded) & 407 & 308 & $<0.001$ & 304 & 251 & $<0.001$ & 287 & 227 & $<0.001$ \\
\hline Direct health care costs & 2,571 & 2,627 & & 2,796 & 2,704 & & 2,874 & 2,778 & \\
\hline Indirect costs, foregone earnings & $(907)$ & & & 759 & & & 238 & & \\
\hline Sum of direct and indirect costs & 1,665 & 2,627 & & 3,555 & 2,704 & & 3,112 & 2,778 & \\
\hline Attributable costs & $(962)$ & & & 851 & & & 334 & & \\
\hline Social transfer payments & 9,643 & 9,575 & & 10.492 & 10.082 & & 10.480 & 10.217 & \\
\hline
\end{tabular}

NOS: not otherwise specified

\section{Limitations of the study}

The current study included all patients who had received a diagnosis of stroke. A study of the registration procedure suggests that approximately $85-90 \%$ of registrations in the NPR are correct [38]. However, it is likely that some diagnoses are erroneous due to incorrect registration, or variation in the registration procedure or diagnostic criteria [24].

Stroke patients are likely to have a high registration rate in the national register, but rates may be underestimated through the failure to recognize patients with early or minor symptoms, or those who have contact with the primary sector, since such contacts are registered without a diagnosis. In general, the sample in the database comprises almost the entire national patient population. As the study is based on registry data only resource use covered by these registers is included in the analysis. Danish registers do not cover home nursing or nursing homes, so the cost estimates do not quantify the full cost of the disease.

\section{Conclusion}

Stroke causes significant mortality. Stroke survivors and their relatives experience significant consequences in terms of increased morbidity and, in turn, significantly higher health-related and social-transfer costs and slightly 
lower levels of employment and income compared with a matched control group of people without a diagnosis of stroke. The consequences for partners are not negligible and account for approximately one-third of the total familiar costs. Costs are highest among younger adults due to loss of work and the resulting higher indirect costs. Stroke patients have significantly more health-related contacts and present social vulnerability years before their incident. The significance of morbidities prior to the onset of stroke should be examined further to identify and treat groups at high risk of developing chronic disease so that its costs and consequences for patients, their families and society can be reduced.

\section{Abbreviations \\ NOS: Not otherwise specified; NPR: National Patient Registry.}

\section{Competing interests}

The authors declare that they have no competing interests.

\section{Authors' contributions}

PJ conceived, substantially contributed to the design and carried out the study, interpreted the results, and is the main author. HKI commented on the design, analysis and contributed to writing the article. RI and JK made substantial contributions to the design, acquisition and analysis of data and commented on the article. All authors have read and approved the final manuscript.

\section{Authors' information}

Not applicable.

\section{Acknowledgements}

The study is part of a larger study supported by the Center of Healthy Aging, Faculty of Health Sciences, University of Copenhagen, with the purpose of identifying the economic burden of neurological diseases.

\section{Funding}

Was made available from departmental research resources. None of the funders had any influence on the study design, the collection, analysis or interpretation of the data, the writing of the report, or the decision to submit the paper for publication.

\section{Author details}

'Danish Center for Sleep Medicine, Department of Clinical Neurophysiology, Faculty of Health Sciences, University of Copenhagen, Glostrup Hospital, DK 2600, Copenhagen, Glostrup, Denmark. ${ }^{2}$ Stroke Unit, Department of Neurology, Faculty of Health Sciences, University of Copenhagen, Glostrup Hospital, Copenhagen, Denmark. ${ }^{3} 2$ minds, Klosterport 4E, 4, Aarhus, Denmark. ${ }^{4}$ Danish Institute for Health Services Research, Copenhagen, Denmark.

Received: 25 January 2015 Accepted: 22 September 2015 Published online: 13 October 2015

\section{References}

1. Cox AM, McKevitt C, Rudd AG, Wolfe CD. Socioeconomic status and stroke Lancet Neurol. 2006;5:181-8.

2. Chevreul K, Durand-Zaleski I, Gouepo A, Fery-Lemonnier E, Hommel M, Woimant F. Cost of stroke in France. Eur J Neurol. 2013;20:1094-100.

3. Hoffmann TC, Lindley RI. Stroke care in Australia: why is it still the poo cousin of health care? Med J Aust. 2013;198:246-7.

4. Fattore G, Torbica A, Susi A, Giovanni A, Benelli G, Gozzo M, et al. The social and economic burden of stroke survivors in Italy: a prospective, incidencebased, multi-centre cost of illness study. BMC Neurol. 2012:12:137.

5. Bottacchi E, Corso G, Tosi P, Morosini MV, De FG, Santoni L, et al. The cost of first-ever stroke in Valle d'Aosta, Italy: linking clinical registries and administrative data. BMC Health Serv Res. 2012;12:372.
6. Persson J, Ferraz-Nunes J, Karlberg I. Economic burden of stroke in a large county in Sweden. BMC Health Serv Res. 2012;12:341.

7. Lopez-Bastida J, Oliva MJ, Worbes CM, Perestelo PL, Serrano-Aguilar P, MontonAlvarez F. Social and economic costs and health-related quality of life in stroke survivors in the Canary Islands, Spain. BMC Health Serv Res. 2012;12:315.

8. Francescutti C, Mariotti S, Simon G, D'Errigo P, Di BR. The impact of stroke in Italy: first step for a National Burden of Disease Study. Disabil Rehabil. 2005;27:229-40.

9. Butt M, Dwivedi G, Shantsila A, Khair OA, Lip GY. Left ventricular systolic and diastolic function in obstructive sleep apnea: impact of continuous positive airway pressure therapy. Circ Heart Fail. 2012;5:226-33.

10. van EM, Van Heugten CM, Evers SM. The economic impact of stroke in The Netherlands: the euro-Restore4Stroke study. BMC Public Health. 2012:12:122.

11. Lee $Y C$, Chen YM, Hsueh IP, Wang YH, Hsieh CL. The impact of stroke: insights from patients in Taiwan. Occup Ther Int. 2010;17:152-8.

12. Parag V, Hackett ML, Yapa CM, Kerse N, McNaughton H, Feigin VL, et al. The impact of stroke on unpaid caregivers: results from The Auckland Regional Community Stroke study, 2002-2003. Cerebrovasc Dis. 2008;25:548-54.

13. Adelman SM. The National Survey of Stroke. Economic impact. Stroke. 1981;12:169-87.

14. Pereira RA, dos Santos EB, Fhon JR, Marques S, Rodrigues RA. [Burden on caregivers of elderly victims of cerebrovascular accident]. Rev Esc Enferm USP. 2013:47:185-92.

15. Das S, Hazra A, Ray BK, Ghosal M, Banerjee TK, Roy T, et al. Burden among stroke caregivers: results of a community-based study from Kolkata, India. Stroke. 2010;41:2965-8.

16. Lutz BJ, Young ME. Rethinking intervention strategies in stroke family caregiving. Rehabil Nurs. 2010;35:152-60.

17. Carod-Artal FJ, Ferreira CL, Trizotto DS, Menezes MC. Burden and perceived health status among caregivers of stroke patients. Cerebrovasc Dis. 2009;28:472-80.

18. Lynge E, Sandegaard JL, Rebolj M. The Danish National Patient Register. Scand J Public Health. 2011;39:30-3.

19. Jennum P, Zoetmulder M, Korbo L, Kjellberg J. The health-related, social, and economic consequences of parkinsonism: a controlled national study. J Neurol. 2011;258:1497-506.

20. Jennum P, Gyllenborg J, Kjellberg J. The social and economic consequences of epilepsy: a controlled national study. Epilepsia. 2011;52:949-56.

21. Jennum P, Kjellberg J. Health, social and economical consequences of sleepdisordered breathing: a controlled national study. Thorax. 2011;66:560-6.

22. Jennum P, Knudsen S, Kjellberg J. The economic consequences of narcolepsy. J Clin Sleep Med. 2009;5:240-5.

23. Pedersen CB. The Danish Civil Registration System. Scand J Public Health 2011:39:22-5.

24. Wildenschild C, Mehnert F, Thomsen RW, Iversen HK, Vestergaard K, Ingeman A, et al. Registration of acute stroke: validity in the Danish Stroke Registry and the Danish National Registry of Patients. Clin Epidemiol. 2014;6:27-36.

25. Gustavsson A, Svensson M, Jacobi F, Allgulander C, Alonso J, Beghi E, et al. Cost of disorders of the brain in Europe 2010. Eur Neuropsychopharmacol. 2011;21:718-79.

26. Zorowitz RD, Gillard PJ, Brainin M. Poststroke spasticity: sequelae and burden on stroke survivors and caregivers. Neurology. 2013;80:S45-52.

27. Jaracz K, Grabowska-Fudala B, Kozubski W. Caregiver burden after stroke: towards a structural model. Neurol Neurochir Pol. 2012:46:224-32.

28. Kruithof WJ, Visser-Meily JM, Post MW. Positive caregiving experiences are associated with life satisfaction in spouses of stroke survivors. J Stroke Cerebrovasc Dis. 2012;21:801-7.

29. Carek V, Norman P, Barton J. Cognitive appraisals and posttraumatic stress disorder symptoms in informal caregivers of stroke survivors. Rehabil Psychol. 2010;55:91-6.

30. Demaerschalk BM, Hwang HM, Leung G. US cost burden of ischemic stroke: a systematic literature review. Am J Manag Care. 2010;16:525-33.

31. Jennum P, Ibsen R, Pedersen SW, Kjellberg J. Mortality, health, social and economic consequences of amyotrophic lateral sclerosis: a controlled national study. J Neurol. 2013;260:785-93.

32. Jennum P, Wanscher B, Frederiksen J, Kjellberg J. The socioeconomic consequences of multiple sclerosis: A controlled national study. Eur Neuropsychopharmacol. 2011.

33. Jennum P, Ibsen R, Petersen ER, Knudsen S, Kjellberg J. Health, social, and economic consequences of narcolepsy: a controlled national study evaluating the societal effect on patients and their partners. Sleep Med. 2012;13:1086-93. 
34. Andersen G, Christensen D, Kirkevold M, Johnsen SP. Post-stroke fatigue and return to work: a 2-year follow-up. Acta Neurol Scand. 2012;125:248-53.

35. Andersen HE, Eriksen K, Brown A, Schultz-Larsen K, Forchhammer BH. Follow-up services for stroke survivors after hospital discharge-a randomized control study. Clin Rehabil. 2002;16:593-603.

36. Langagergaard V, Palnum KH, Mehnert F, Ingeman A, Krogh BR, Bartels P, et al. Socioeconomic differences in quality of care and clinical outcome after stroke: a nationwide population-based study. Stroke. 2011;42:2896-902.

37. Kuper H, Adami HO, Theorell T, Weiderpass E. The socioeconomic gradient in the incidence of stroke: a prospective study in middle-aged women in Sweden. Stroke. 2007;38:27-33.

38. Mosbech J, Jorgensen J, Madsen M, Rostgaard K, Thornberg K, Poulsen TD. [The national patient registry. Evaluation of data quality]. Ugeskr Laeger. 1995; 157:3741-5

\section{Submit your next manuscript to BioMed Central and take full advantage of:}

- Convenient online submission

- Thorough peer review

- No space constraints or color figure charges

- Immediate publication on acceptance

- Inclusion in PubMed, CAS, Scopus and Google Scholar

- Research which is freely available for redistribution 